\title{
Unexpected perturbations training improves balance control and voluntary stepping times in older adults - a double blind randomized control trial
}

\author{
Ilan Kurz ${ }^{1}$, Yoav Gimmon ${ }^{1}$, Amir Shapiro ${ }^{2}$, Ronen Debi ${ }^{3}$, Yoram Snir ${ }^{4}$ and Itshak Melzer ${ }^{1 *}$
}

\begin{abstract}
Background: Falls are common among elderly, most of them occur while slipping or tripping during walking. We aimed to explore whether a training program that incorporates unexpected loss of balance during walking able to improve risk factors for falls.

Methods: In a double-blind randomized controlled trial 53 community dwelling older adults (age $80.1 \pm 5.6$ years), were recruited and randomly allocated to an intervention group $(n=27)$ or a control group $(n=26)$. The intervention group received 24 training sessions over 3 months that included unexpected perturbation of balance exercises during treadmill walking. The control group performed treadmill walking with no perturbations. The primary outcome measures were the voluntary step execution times, traditional postural sway parameters and Stabilogram-Diffusion Analysis. The secondary outcome measures were the fall efficacy Scale (FES), self-reported late life function (LLFDI), and Performance-Oriented Mobility Assessment (POMA).

Results: Compared to control, participation in intervention program that includes unexpected loss of balance during walking led to faster Voluntary Step Execution Times under single $(p=0.002$; effect size $[E S]=0.75)$ and dual task $(p=0.003 ;[E S]=0.89)$ conditions; intervention group subjects showed improvement in Short-term Effective diffusion coefficients in the mediolateral direction of the Stabilogram-Diffusion Analysis under eyes closed conditions $(p=0.012$, $[E S]=0.92)$. Compared to control there were no significant changes in FES, LLFDI, and POMA.

Conclusions: An intervention program that includes unexpected loss of balance during walking can improve voluntary stepping times and balance control, both previously reported as risk factors for falls. This however, did not transferred to a change self-reported function and FES.
\end{abstract}

Trial registration: ClinicalTrials.gov Registration number: NCT01439451.

Keywords: Aging, Falls, Unexpected perturbation of balance, Step execution, Postural stability

\section{Background}

Falls are a major problem among elderly population; they are the leading cause of injury above the age of 65 [1]. Of those who fall in the U.S., 20 to $30 \%$ suffer moderate to severe injuries that reduce mobility and independence, and

\footnotetext{
* Correspondence: itzikm@bgu.ac.il

${ }^{1}$ Schwartz Movement Analysis \& Rehabilitation Laboratory, Department of Physical Therapy, Recanati School for Community Health Professions, Faculty of Health Sciences, Ben-Gurion University of the Negev, P.O.B. 653, Beer-Sheva 84105, Israel

Full list of author information is available at the end of the article
}

increase the risk of death [2]. The financial impact in 2000, adjusted for inflation, was $\$ 30$ billion and is expected to reach $\$ 67.7$ billion by 2020 [1].

Walking is the major activity in which large proportion of falls in older adults occurs [3]. Sixty percent of outdoor falls among older adults resulted from slips or trips [4]. Even among older adults capable of independent walking, there could be a substantial decline in balance performance, which does not become evident until a slip or a trip happens [5]. In fact, the inability to step rapidly in response to unexpected loss of balance ultimately

\section{Biomed Central}


determines whether a fall occurs [6, 7]. Thus, a better way to improve balance, improve stepping and reduce risk of falls may be to direct preventive efforts towards older adults who have not yet fallen. Until recently these balance recovery responses were considered hardwired postural reflexes that could not be influenced by training. However, [8-10] it was showed that older adults were able to adapt in a reactive manner after participation in a perturbation exercises that challenged the mechanisms responsible for dynamic stability (i.e., increase in base of support and counter-rotating segments around the center of mass).

A number of studies have begun to examine the effect of perturbation training on balance of older adults. Shimada et al. [11] found improvement in mobility and a trend to fall reduction after split treadmill training. This training method is a very unnatural condition, given that most people walk with the same velocity in each leg. Other studies have other issues. Pai et al. [12] showed a rapid decrease in loss of balance in response to multiple presentations of a slip perturbation after rising from sit to stand. Mansfield et al [13] found that older adults with a history of falls or instability reduced the frequency of multi-step reactions and foot collisions after perturbation training while standing or walking in place. The training methods perturb the balance of their participants from sit to stand or during standing or walking in place, which may not be as relevant in a natural setting as might be a perturbation while walking. Melzer and Oddsson [14] found improvement in voluntary stepping, and balance control, in an exercises program that incorporate mild external balance perturbation exercises applied by the instructors; and Halvarsson et al. [15] found that old fallers that suffered from fear of falling, decreased their fear of falling, and voluntary stepping times during dual-task performance and increased velocity of walking post perturbation training.. However, in these program the perturbations of posture were expected, and not random. Recently it was showed that unidirectional translational treadmill training (i.e., a laboratoryinduced trip) reduced falls $[16,17]$. Bhatt et al. [18] found that inducing unannounced right-leg slips, participants significantly reduced fall and balance loss incidence. Pai, et al. [19] found that a single session of repeated-slip exposure reduced older adults' annual risk of falls from 34 to $15 \%(p<0.05)$ especially among those who had history of falls. The above protocol provided an anterior perturbation, causing a backwards "slip" initiated always by on the right foot. Participants might have learned and expected the right-leg slips perturbations. In a recent meta-analysis [20] that include 8 perturbation-based balance training studies $(n=404)$ participants reported fewer falls than those in the control groups.

Motivated by the above perturbations training studies and trying to accommodate for some of the issues mentioned above (i.e., perturbation training while standing or walking in place; highly predictable repeated-right leg slip exposure; a very unnatural walking on split treadmill), we aimed to explore whether unexpected multidirectional perturbation training while walking on a treadmill [21] can reduce risks of falls in independent older adults. A perturbation exercise while walking provides a more realistic balance training that is sufficiently task-specific so that responses on this training regime will be more likely to be transferred to other measures of balance control and voluntary stepping measures.

Our hypotheses were that following exposure to a gait training program that includes unexpected perturbations exercises during walking will significantly improve voluntary stepping times as well as balance control in older adults, two factors that are associated with falls and injuries related with falls [22-27]. We believe that perturbation exercises that will challenge both balance control during walking as well as trigger a quick stepping responses to avoid fall during walking. These postural response following an external perturbation receives a higher priority than a voluntary action thus can be incorporated into centrally programmed voluntary movements [28]. This concept should be of importance for balance training and it further supports the notion that postural perturbations should be incorporated into balance training programs.

\section{Methods \\ Participants}

Community dwelling older adults were recruited from two protected housing institutes. Eligibility criteria were: 70 years or older; walking independently; Mini-Mental Score higher than 24; no severe focal muscle weakness or blindness; no known neurological disorders; no metastatic cancer. Out of 72 seniors who were assessed for eligibility, 19 were excluded (see Fig. 1). All subjects provided a medical waiver signed by their primary care physician clearing them to participate in moderate physical exercise. The study was approved by the Helsinki committee of Barzilai University medical center, Ashkelon, Israel (ClinicalTrials.gov Registration number \#NCT01439451). All subjects signed an informed consent statement.

\section{Study design}

After eligibility and baseline assessments subjects were randomized to two blocks (27 and 26 subjects, respectively). In the first site, 28 subjects were randomly allocated to 2 intervention groups and in the second site 25 subjects were randomly allocated to 2 intervention groups. The subjects random allocation was made by an investigator not involved in the assessments using computer random allocation software (Random allocation software version 1.1, Isfahan Iran). Performance-based and laboratory balance functions were tested before and after the training 


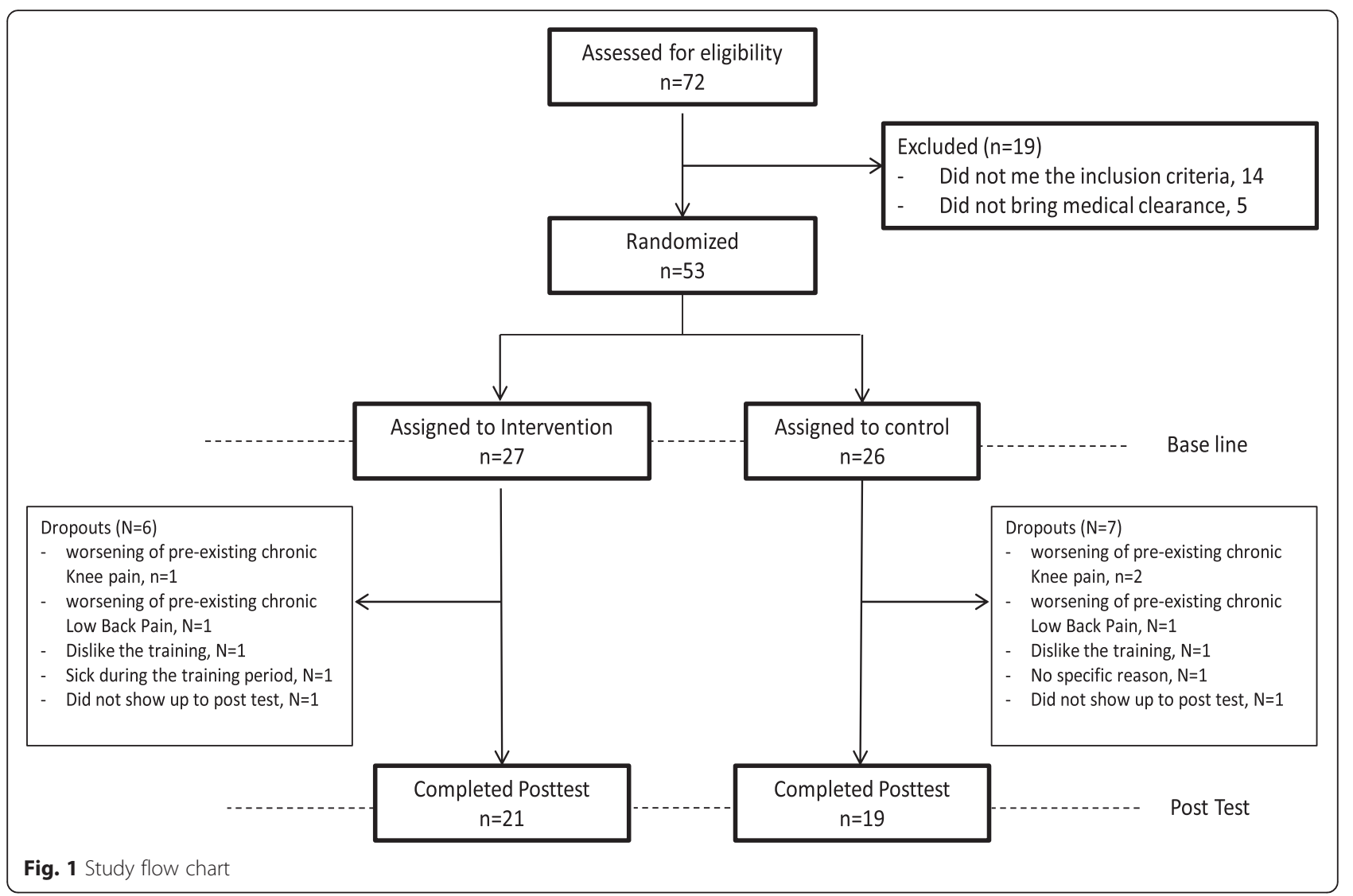

period by a blinded investigator. All assessment sessions were performed at the same time of day, and in the same order.

\section{Training programs}

We used a mechatronic device that provides controlled and unexpected anterior-posterior and Medio-lateral platform translations during a single belt, treadmill walking (details in reference [21] and Fig. 2a-c). The intervention group received 24 training sessions, twice a week for 12 weeks. Each session lasted for about $20 \mathrm{~min}$ and included $3 \mathrm{~min}$ warm-up walking in subject own preferred pace, 14 min of unannounced perturbations exercises, given in random direction order, during walking (every 20-40 s) and $3 \mathrm{~min}$ of cool down walking. During the training sessions the subjects were instructed to walk on a treadmill, wearing their own walking shoes, with their hands free to swing; there were no handrails on the treadmill. To prevent injury if loss of balance occurred during the treadmill walking, the subject wore a loose safety harness that could arrest the fall, but that allowed the subject to walk comfortably as well as freedom to execute recovery reactions without suspension (Fig. 2a). The instructions given to the subjects were:
"Walk as naturally as possible at your preferred stride frequency". The treadmill's walking speed was adjusted to the subjects own preferred speed.

The perturbations were in anterior-posterior direction (i.e., sudden acceleration or stop of treadmills belt) and sudden medio-lateral horizontal translation of the treadmill that challenges the medio-lateral dynamic control. During all sessions, $400 \mathrm{~ms}$ horizontal surface translations were delivered as the subject walked on the treadmill. The velocity profiles were triangular waveforms with peak velocities of $0.1-3.2 \mathrm{~m} / \mathrm{s}$, resulting in displacements of $1-18 \mathrm{~cm}$ and peak accelerations of $0.5-16.0 \mathrm{~m} / \mathrm{s}^{2}$. Perturbation timing was preset and therefore was not given in a specific phase of the gait cycle or to a specific leg. The perturbation training program had 24 levels of difficulty with increasing levels of perturbations (i.e., increased displacement, velocity and accelerations of the horizontal translations, see Table 1). The difficulty level was adjusted according to the subject abilities, starting from the lowest level of $1 \mathrm{~cm}$ displacement at $0.1 \mathrm{~m} / \mathrm{s}$ velocity and $0.5 \mathrm{~m} / \mathrm{s}^{2}$ acceleration at the first training session. If the subject was able to recover from all perturbations during the session (i.e., did not fell during the session) and felt that he can be further challenged, a higher level of perturbation was introduced in the next session. If not, the same level of perturbation was introduced again 


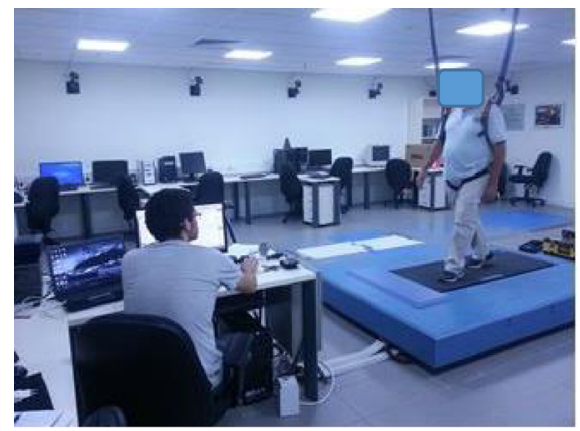

(A)

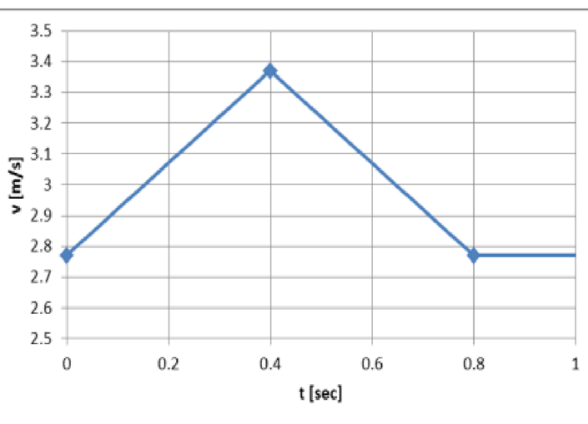

(B)
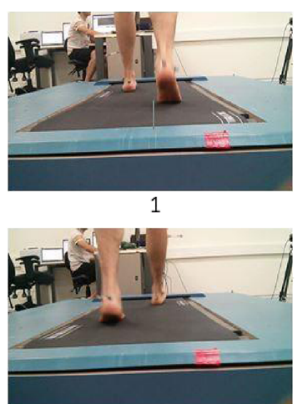

5 (Perturbation start)

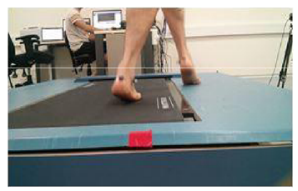

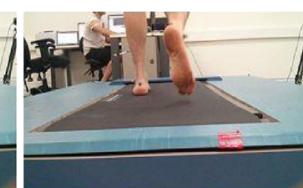

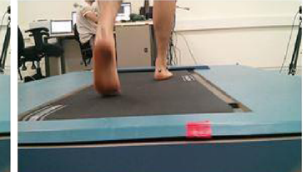

6

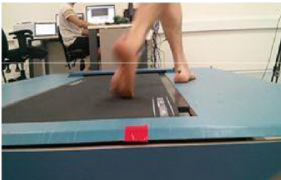

10

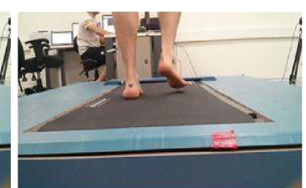

3

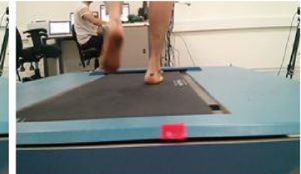

7

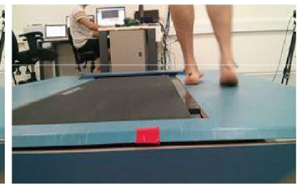

11

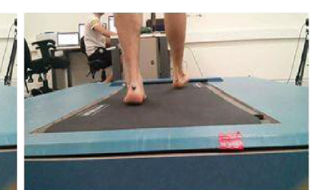

4

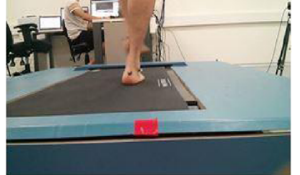

8

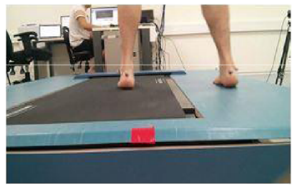

12

(C)

Fig. 2 The perturbation treadmill system used a Photo of the perturbation system during balance training. The system is compose of a motor-driven treadmill, mounted on a moving platform, motion controller, safety harness and an operator station; $\mathbf{b}$ the perturbations velocity control diagram during training delivered unpredictably in forward, backward, left, and right directions. Note those are actual measurements taken during perturbation training. c Example of the perturbation applied during the treadmill walking training (c1-c12). The perturbation applied unpredictably (c5) by horizontal movement of the platform towards the left side during the right foot initial contact-loading response phases of gait cycle. The participant right foot was slipped unpredictably to the left while walking in the center of the platform. The participants performed a cross over stepping response by his left foot (c6-c9), than additional side step was performed by the right foot stepping outside the treadmill (c10-c12)

until successfully dealt with. Fall during the training session was defined as load cell sensors detected $30 \%$ or more body weight suspended by the safety harness.

The control group received 24 sessions, twice a week for 12 weeks, 20 min treadmill walking on the same treadmill but without unexpected perturbations. similar to the intervention group the control group subjects walked at their own preferred speed and in their own walking shoes, with their hands free to swing; there were no handrails on the treadmill, thus they wore a loose safety harnesses that allowed comfortable walking. Since both group trained on the same system, they were blinded to the allocation to intervention or control group.

\section{Assessments}

For the balance control testing the subjects were instructed to stand barefoot as still as possible and on a force platform in a standardized stance, their feet close together. Ten 30-s quiet-standing trials with eyes blindfolded. Center of pressure and ground reaction force data were collected with a Kistler 9287 force platform (Kistler Instrument Corp, Amherst, NY, USA), sampled at a frequency of $100 \mathrm{~Hz}$. Evaluation of balance control was made using both traditional measure of postural sway in eyes closed condition (e.g. ML-sway, AP-sway, mean sway velocity, and Mean sway area), we also calculated the Stabilogram-Diffusion Analysis parameters from 
Table 1 Details of Protocol Used in the perturbation intervention training program

\begin{tabular}{|c|c|c|c|c|}
\hline $\begin{array}{l}\text { The training } \\
\text { sessions \# }\end{array}$ & $\begin{array}{l}\text { platform } \\
\text { displacement (cm) }\end{array}$ & $\begin{array}{l}\text { platform peak } \\
\text { velocity }(\mathrm{cm} / \mathrm{s})\end{array}$ & $\begin{array}{l}\text { platform peak } \\
\text { acceleration }\left(\mathrm{cm} / \mathrm{s}^{2}\right)\end{array}$ & $\begin{array}{l}\text { Number of unannounced } \\
\text { random Perturbations per } \\
\text { minute (forward, backward, left, right) }\end{array}$ \\
\hline 1 & $1-2 \mathrm{~cm}$ & $0.1-0.5 \mathrm{~m} / \mathrm{s}$ & $0.5-3.0 \mathrm{~m} / \mathrm{s}^{2}$ & 1 \\
\hline 2 & $2-3 \mathrm{~cm}$ & $0.2-0.6 \mathrm{~m} / \mathrm{s}$ & $0.7-5.0 \mathrm{~m} / \mathrm{s}^{2}$ & 2 \\
\hline 3 & $3-4 \mathrm{~cm}$ & $0.4-0.6 \mathrm{~m} / \mathrm{s}$ & $0.9-7.0 \mathrm{~m} / \mathrm{s}^{2}$ & 1 \\
\hline 4 & $3-5 \mathrm{~cm}$ & $0.5-0.7 \mathrm{~m} / \mathrm{s}$ & $1.1-7.0 \mathrm{~m} / \mathrm{s}^{2}$ & 2 \\
\hline 5 & $4-6 \mathrm{~cm}$ & $0.5-0.8 \mathrm{~m} / \mathrm{s}$ & $1.5-8.0 \mathrm{~m} / \mathrm{s}^{2}$ & 2 \\
\hline 6 & $5-6 \mathrm{~cm}$ & $0.5-1.0 \mathrm{~m} / \mathrm{s}$ & $2.0-10.0 \mathrm{~m} / \mathrm{s}^{2}$ & 2 \\
\hline 7 & $5-7 \mathrm{~cm}$ & $0.7-1.0 \mathrm{~m} / \mathrm{s}$ & $2.5-12.0 \mathrm{~m} / \mathrm{s}^{2}$ & 2 \\
\hline 8 & $6-7 \mathrm{~cm}$ & $0.8-1.2 \mathrm{~m} / \mathrm{s}$ & $3.0-14.0 \mathrm{~m} / \mathrm{s}^{2}$ & 3 \\
\hline 9 & $6-8 \mathrm{~cm}$ & $1.0-1.5 \mathrm{~m} / \mathrm{s}$ & $3.5-16.0 \mathrm{~m} / \mathrm{s}^{2}$ & 2 \\
\hline 10 & $7-8 \mathrm{~cm}$ & $1.2-1.8 \mathrm{~m} / \mathrm{s}$ & $4.0-16.0 \mathrm{~m} / \mathrm{s}^{2}$ & 3 \\
\hline 11 & $7-9 \mathrm{~cm}$ & $1.5-2.0 \mathrm{~m} / \mathrm{s}$ & $5.0-16.0 \mathrm{~m} / \mathrm{s}^{2}$ & 2 \\
\hline 12 & $8-9 \mathrm{~cm}$ & $1.6-2.2 \mathrm{~m} / \mathrm{s}$ & $6.0-16.0 \mathrm{~m} / \mathrm{s}^{2}$ & 3 \\
\hline 13 & $8-10 \mathrm{~cm}$ & $1.8-2.5 \mathrm{~m} / \mathrm{s}$ & $7.0-16.0 \mathrm{~m} / \mathrm{s}^{2}$ & 2 \\
\hline 14 & $9-10 \mathrm{~cm}$ & $2.0-2.6 \mathrm{~m} / \mathrm{s}$ & $8.0-16.0 \mathrm{~m} / \mathrm{s}^{2}$ & 3 \\
\hline 15 & $9-11 \mathrm{~cm}$ & $2.0-2.8 \mathrm{~m} / \mathrm{s}$ & $9.0-16.0 \mathrm{~m} / \mathrm{s}^{2}$ & 2 \\
\hline 16 & $10-11 \mathrm{~cm}$ & $2.2-3.0 \mathrm{~m} / \mathrm{s}$ & $10.0-16.0 \mathrm{~m} / \mathrm{s}^{2}$ & 3 \\
\hline 17 & $11-14 \mathrm{~cm}$ & $2.4-3.0 \mathrm{~m} / \mathrm{s}$ & $11.0-16.0 \mathrm{~m} / \mathrm{s}^{2}$ & 2 \\
\hline 18 & $12-14 \mathrm{~cm}$ & $2.5-3.0 \mathrm{~m} / \mathrm{s}$ & $12.0-16.0 \mathrm{~m} / \mathrm{s}^{2}$ & 3 \\
\hline 19 & $13-15 \mathrm{~cm}$ & $2.6-3.0 \mathrm{~m} / \mathrm{s}$ & $13.0-16.0 \mathrm{~m} / \mathrm{s}^{2}$ & 2 \\
\hline 20 & $14-15 \mathrm{~cm}$ & $2.6-3.2 \mathrm{~m} / \mathrm{s}$ & $14.0-16.0 \mathrm{~m} / \mathrm{s}^{2}$ & 3 \\
\hline 21 & $14-16 \mathrm{~cm}$ & $2.8-3.2 \mathrm{~m} / \mathrm{s}$ & $14.0-16.0 \mathrm{~m} / \mathrm{s}^{2}$ & 2 \\
\hline 22 & $15-17 \mathrm{~cm}$ & $2.8-3.2 \mathrm{~m} / \mathrm{s}$ & $14.0-16.0 \mathrm{~m} / \mathrm{s}^{2}$ & 3 \\
\hline 23 & $16-18 \mathrm{~cm}$ & $2.8-3.2 \mathrm{~m} / \mathrm{s}$ & $14.0-16.0 \mathrm{~m} / \mathrm{s}^{2}$ & 2 \\
\hline 24 & $17-18 \mathrm{~cm}$ & $2.8-3.2 \mathrm{~m} / \mathrm{s}$ & $14.0-16.0 \mathrm{~m} / \mathrm{s}^{2}$ & 3 \\
\hline
\end{tabular}

The 24 training sessions. Each session lasted $20 \mathrm{~min}$, included 3 min warm-up treadmill walking, 14 min of perturbations during comfortable treadmill walking, given in random direction (right, left, forward and backwards), and 3 min of cool down walking. The perturbation training program had 24 levels of difficulty with increasing levels of perturbations (i.e., increased displacement, velocity and accelerations of the horizontal translations). During each session, the listed platform translation unannounced perturbations were delivered in an unpredictable randomized sequence, in the directions indicated (forward, backward, left, and right). Perturbations for the treadmill walking were occur randomly (i.e., occurs in all phases of gait cycle) in order to increase the ecological validity. The perturbation was delivered after 20-30 s approximately every 20 strides and was triggered randomly

Center of pressure data. The Stabilogram-Diffusion Analysis plots (SDA) of the mean square center of pressure displacement (Critical Displacement, Cd) vs. time interval (Critical Time, $\mathrm{Ct}$ ) parameters were extracted from the center of pressure trajectories. The SDA plots derived from COP trajectories during standing indicate the presence of two different behaviors depending on the time interval of interest. For shorter time intervals (less than $1 \mathrm{~s}$ ) the COP tend to drift away from a relative equilibrium point while longer time intervals (more than $1 \mathrm{~s}$ ) the COP tends to return to a relative equilibrium point [29]. It has been suggested that long-term region is governed by closed-loop control mechanisms whereas the postural control systems operate with sensory feedback, while during the short-term region the postural control system is governed by open-loop control mechanisms whereas the postural control systems operate without sensory feedback.
The transition point between the short-term and long-term behavior has been termed the Critical Time $(\mathrm{Ct})$ and sway displacement has been termed the Critical Displacement (Cd) at which closed-loop control begins to dominate sway behavior. It was described in detail by Collins and De Luca $[29,30]$. The SDA method has been adopted by our research group, we found that SDA parameters (e.g., Critical Displacement $(C d)$, and Short-term Effective diffusion coefficients $(D s)$ were able to predict falls [26] and injury from fall [27].

For the Voluntary Step Execution Test participants were instructed to stand with both feet on a single force platform, they were instructed to voluntary step as quickly as possible following a somatosensory cue, given randomly on one of their feet $[24,31,32]$. Center of pressure movement and ground reaction force data were collected from the force platform, sampled at a frequency of $100 \mathrm{~Hz}$. A total of 
8 trials were conducted in single task condition, 4 forward and 4 backward as well as in dual task conditions. The average result across task condition was used for statistical analysis. For the single task, subjects viewed an " $\mathbf{X}$ " displayed on a screen in front of them. During the dual task they conducted the same test while performing the modified Stroop task [33, 34]. Specific temporal events were extracted from the step execution data: (a) Reaction Time; (b) Foot Contact Time; (c) Preparation Time; (d) Swing Time; as previously described in detail [24, 31, 32]. The foot contact times (i.e., stepping time) and reaction time duration especially in dual task condition were able to predict future fall [23] and injury from fall [22], thus both were selected as the primary outcome measure in the present study.

The secondary outcome measures were the self-reported function (Late Life Function and Disability Instrument (LLFDI)) [35], Fall Efficacy Scale (FES) [36] and performed the Performance-Oriented Mobility Assessment (POMA) [37].

\section{Sample size}

Sample size requirements were calculated based on AP postural sway in eyes closed condition and voluntary step execution times, both were found to predict injury from fall in older adults $([22,27]$ respectively). For both calculations, the probability of type I error was 0.05 , and probability of type II error was 0.2 . Based on data presented by Kurz et al. [27] that found that the traditional AP postural sway in eyes closed condition was $42.3 \mathrm{~mm}$ in older adults who were injured as a result of falling compared with $32.6 \mathrm{~mm}$ in non-fallers older adults; and Melzer et al. [22] found that the step execution times (i.e., foot contact time) in dual task condition of older adults who fell and as a result injured were $217 \mathrm{~ms}$ longer than those of non-fallers (1,394 ms vs. $1,177 \mathrm{~ms})$. Using net reduction values $(9.7 \mathrm{~mm}$ and $217 \mathrm{~ms}$, respectively) in combination with the initial variance estimates (standard deviations of $11 \mathrm{~mm}$ and $250 \mathrm{~ms}$, respectively), it was determined that 21 and 22 participants per group would be required, respectively. To account for reported attrition rates of about $25 \%$ in studies involving older adults [38], we decided to include about 27 participants in each group for a total of $54(22 \times 1.25=27)$.

\section{Data and statistical analysis}

PASW Statistics version 18.0 was used for statistical calculations (Somers, NY, USA, version 18). Baseline characteristics were compared using Independent $t$-test and Mann-Whitney U-tests for continuous and ordinal variables, respectively. To analyze the effect of the intervention program a two-way repeated-measures ANOVA for within subjects (pre vs. post-test) and between group (perturbation intervention vs. control group) was performed.
Since age was significantly different between intervention and control group subjects, we included age as a covariate in the analyses. The primary outcome variables were the parameters that we previously found to be related to falls and injury from fall: the step execution times in single and dual task conditions (i.e., foot contact-time) and step reaction time, traditional postural sway in eyes closed condition (ML- and AP- sway, sway velocity and mean sway area) as well as Stabilogram diffusion Analysis parameters (Critical Displacement $(C d)$, and Short-term Effective diffusion coefficients $(D s)$ in eyes closed condition. The secondary outcome measures were LLFDI, FES and POMA. An intention to treat analysis was conducted by carrying the last obtained measurements forward for those subjects who did not complete all aspects of the study. Adjustment of level of significance for multiple comparisons were made. For each testing procedure (e.g., single task voluntary stepping, dual task voluntary stepping, postural sway and SDA), a full Bonferroni correction was used to achieve an overall significance level of 0.05.

For the significant improvement the Effect Size (ES) of Hedge's $g$ was calculated. The ES of $g$ was calculated by taking the difference between the means of both groups divided by the average population standard deviation (SD). To estimate the SD for $g$, baseline estimated SDs of both groups was pooled. When interpreting correlation magnitudes: $0.0-0.2$ is considered small, $0.2-0.5$ is considered moderate and $0.5-0.8$ is considered large [39].

\section{Results}

Other than age and height there were no significant differences between the groups at baseline (Table 2). During the training period we had 6 drop outs in the intervention group and 7 in the control group (Fig. 1).

Table 3 show that the perturbation training resulted in a significant group-by-time decrease in AP-sway $(p=0.012$, $[E S]=0.59)$. There were also a trend towards a group-bytime decrease with a large effect size in sway velocity, sway area and ML-sway post-training $(p=0$. 115 , $[\mathrm{ES}]=0.72 ; p=0.119,[\mathrm{ES}]=0.74$; and $p=0.142$, $[E S]=0.58$, respectively); although these differences were not statistically significant, the effect size is considered to be moderate. The Stabilogram-Diffusion analysis in eyes closed condition showed a significant group-bytime decrease in Dxs, $(p=0.012,[\mathrm{ES}]=0.78)$ and a trend towards significance in Cdy and Dys $(p=0.028$, $[\mathrm{ES}]=0.92$; and $p=0.095, \quad[\mathrm{ES}]=0.65$, respectively) (Table 4).

Table 5 shows that the perturbation training resulted a significant group-by-time interaction for foot contact time of the voluntary step execution in both the single and dual task conditions $(p=0.002$, effect size $[\mathrm{ES}]=0.75$ and $p=0.003$ effect size $[\mathrm{ES}]=0.89$ respectively). In addition, a significant group-by-time 
Table 2 Baseline characteristics of intervention and reference group subjects: descriptive statistics and group comparisons. Values are means \pm SD (95\% confidence interval for means)

\begin{tabular}{|c|c|c|c|}
\hline & Intervention Group $(N=27)$ & Control Group $(N=26)$ & $p$-value \\
\hline Age (year) & $78.2 \pm 5.6$ & $81.4 \pm 4.3$ & 0.05 \\
\hline$\%$ Female & $62 \%$ & $79 \%$ & 0.25 \\
\hline Number drugs/day & $3.3 \pm 1.7$ & $4.2 \pm 2.4$ & 0.18 \\
\hline Height (cm) & $161.5 \pm 10.9$ & $154.9 \pm 6.9$ & 0.03 \\
\hline Weight (Kg) & $70.9 \pm 14.9$ & $65.5 \pm 12.9$ & 0.23 \\
\hline BMI $\left(\mathrm{Kg} / \mathrm{m}^{2}\right)$ & $27.1 \pm 4.4$ & $27.8 \pm 5.1$ & 0.64 \\
\hline Mini-Mental State Examination & $29.1 \pm 1.4$ & $28.7 \pm 1.4$ & 0.49 \\
\hline Fall efficacy scale & $20.5 \pm 4.3$ & $22.8 \pm 10.3$ & 0.36 \\
\hline POMA score & $14.8 \pm 1.3$ & $14.7 \pm 1.4$ & 0.87 \\
\hline \multicolumn{4}{|l|}{ Late life function } \\
\hline - Overall Function & $66.8 \pm 9.6$ & $66.5 \pm 6.7$ & 0.90 \\
\hline - Upper Extremity Function & $82.9 \pm 11.7$ & $79.2 \pm 8.0$ & 0.26 \\
\hline - Basic Lower Extremity Function & $82.4 \pm 12.4$ & $81.3 \pm 13.6$ & 0.79 \\
\hline - Advanced Lower Extremity Function & $59.6 \pm 12.4$ & $61.2 \pm 10.4$ & 0.66 \\
\hline
\end{tabular}

Note: $p$-value compares baselines means in the two groups and, unless otherwise indicated, are based on $t$-test or chi-square. ${ }^{*} P$-value based on Wilcoxon signed rank test and Mann-Whitney $U$ test. Abbreviations: $\mathrm{cm}$ centimeters, $\mathrm{Kg}$ Kilograms, $\mathrm{Kg} / \mathrm{m}^{2} \mathrm{~kg}$ per meter squared

interaction for the voluntary step reaction time in dual task condition $(p=0.010)$, and a trend towards a significant group-by-time interaction for single task condition $(p=0.057)$.

We found no significant group-by-time interaction effect for all components of the LLFDI as well as for FES and POMA.

With respect to side effects and adverse events, during the exercise training program, muscle soreness was experienced by some subjects, especially in the early stage of the training. Those effects were managed by adjusting the training intensity and the symptoms disappeared during training.

\section{Discussion}

The results support in part our main hypotheses, unexpected perturbations training while walking can improve the ability to voluntarily step rapidly and standing balance control in older adults. These parameters have been shown in the past to predict injury from falls $[19,24]$. This shows that the benefits of unexpected perturbation during walking were generalized to other aspects of balance. Our findings are supported by Pai and Bahtt [40] that suggested that the central nervous system makes adaptive improvements in proactive and reactive control of stability as a result of trial and error perturbation practice (i.e., a forward slip). They suggested that the central nervous system

Table 3 The effect of balance training on traditional sway Parameters under eyes closed condition. Values are means \pm 1 SD (95\% confidence interval for means). A full Bonferroni correction (a-level 0.05/4=0.0125) was used for each of the four tests to achieve an overall significance level of 0.05

\begin{tabular}{|c|c|c|c|c|c|}
\hline & Group & Baseline & post-test & $\begin{array}{l}\text { ANOVA (Baseline } \\
\text { to post-test) T }\end{array}$ & $\begin{array}{l}\text { ANOVA (Baseline } \\
\text { to post-test) } T \times G\end{array}$ \\
\hline \multirow[t]{2}{*}{ ML-sway (mm) } & Experimental & $47.9 \pm 15.3$ & $44.6 \pm 15.5$ & $F=0.215$ & $F=2.247$ \\
\hline & Control & $41.4 \pm 8.8$ & $40.5 \pm 8.6$ & $p=0.792$ & $p=0.142$ \\
\hline \multirow[t]{2}{*}{ AP-sway (mm) } & Experimental & $38.6 \pm 13$ & $35.8 \pm 10$ & $F=0.694$ & $F=5.315$ \\
\hline & Control & $33.8 \pm 8$ & $33.9 \pm 7$ & $p=0.711$ & $p=0.012$ \\
\hline \multirow[t]{2}{*}{ Velocity $\left(\mathrm{mm}^{2} / \mathrm{sec}\right)$} & Experimental & $37.7 \pm 12$ & $34.2 \pm 10$ & $F=0.086$ & $F=2.609$ \\
\hline & Control & $35.1 \pm 8$ & $35.0 \pm 9$ & $p=0.770$ & $p=0.115$ \\
\hline \multirow[t]{2}{*}{ Sway Area $\left(\mathrm{mm}^{2}\right)$} & Experimental & $169.3 \pm 9$ & $148 \pm 76$ & $F=0.056$ & $F=2.549$ \\
\hline & Control & $136.6 \pm 48$ & $135 \pm 5$ & $p=0.815$ & $p=0.119$ \\
\hline
\end{tabular}

Note: Comparison of baseline and post-intervention between the two groups based on repeated measures ANOVA (Test $\times$ Group). Abbreviations: $G$ group, $T$ time, $\mathrm{mm}$ millimeters, $\mathrm{s}$ seconds 
Table 4 The effect of balance training on Stabilogram Diffusion Parameters in eyes closed condition. Values are means \pm 1 SD (95\% confidence interval for means). A full Bonferroni correction (a-level 0.05/4 $=0.0125$ ) was used for each of the four tests during the two phases to achieve an overall significance level of 0.05

\begin{tabular}{|c|c|c|c|c|c|}
\hline & Group & Baseline & post-test & $\begin{array}{l}\text { ANOVA (Baseline } \\
\text { to post-test) } T\end{array}$ & $\begin{array}{l}\text { ANOVA (Baseline to } \\
\text { post-test) } T \times G\end{array}$ \\
\hline \multirow[t]{2}{*}{ Short-term Effective diffusion coefficients in $\mathrm{mm}^{2} \mathrm{~s}^{-1}(D \times s)$} & Experimental & $97.9 \pm 71.3$ & $84.7 \pm 58.6$ & $F=0.856$ & $F=5.822$ \\
\hline & Control & $79.18 \pm 38.2$ & $87.4 \pm 48.8$ & $p=0.391$ & $p=0.012$ \\
\hline \multirow[t]{2}{*}{ Short-term Effective diffusion coefficients in $\mathrm{mm}^{2} \mathrm{~s}^{-1}$ (Dys) } & Experimental & $62.9 \pm 54.8$ & $47.3 \pm 34.6$ & $F=0.009$ & $F=2.928$ \\
\hline & Control & $37.2 \pm 29.4$ & $38.4 \pm 27.5$ & $p=0.925$ & $p=0.095$ \\
\hline \multirow[t]{2}{*}{ Critical (Mean-Squared) Displacement in $\mathrm{mm}^{2}(\mathrm{Cdx})$} & Experimental & $131.2 \pm 105$ & $112 \pm 82.7$ & $F=0.038$ & $F=1.916$ \\
\hline & Control & $98.9 \pm 48.7$ & $96.6 \pm 42.7$ & $p=0.847$ & $p=0.157$ \\
\hline \multirow[t]{2}{*}{ Critical (Mean-Squared) Displacement in $\mathrm{mm}^{2}$ (Cdy) } & Experimental & $90.3 \pm 72$ & $69.0 \pm 52.7$ & $F=1.360$ & $F=5.266$ \\
\hline & Control & $62.7 \pm 30$ & $65.9 \pm 30.4$ & $p=0.251$ & $p=0.028$ \\
\hline
\end{tabular}

Note: Comparison of baseline and post-intervention between the two groups based on repeated measures ANOVA (Test $\times$ Group). Abbreviations: $G$ group, $T$ time, $\mathrm{mm}$ millimeters, sec seconds

probably decreases the reliance on feedback corrective mechanisms for successful recovery and builds an internal representations to improve its feedforward control while walking. Pai and Bahtt training [40] used forward slip practice, the training program, while in the present study the direction of the perturbation was highly unpredictable (forward, backward, right and left perturbations), the intervention group subjects were unable to predict the direction of perturbation during the training. Thus it is unlikely that the improvement was due to feedforward control. Our results support the notion that the central nervous system probably increased the reliance on feedback corrective mechanisms for successful recovery. This is supported by the results of the SDA.

The significant improvement in the intervention group and the large effect size in the SDF parameters ( $E S=0.65-0.92)$ in eyes closed conditions are promising. Age-related decrease in SDF parameters are well documented [30,33] and indicates that a COP tends to drift away from the equilibrium point is a predictor to falls in elderly persons $[26,27,29,30,41-43]$. The improvement in the Dxs and $C d y$ as well as tendency towards improvement in Dys of SDA in eyes closed condition showed in this study indicates that the deterioration of balance control could be reversed by perturbation balance training. AP balance control in eyes close condition (Dys and $C d y$ ) were found to be an important risk indicator of falls and injurious falls [26, 27]. Laughton et al. [41] found a greater Dys in elderly fallers compared with the young's, and greater AP and ML sway in older adults who demonstrated lower scores in the POMA. Kurz et al. [27] found that a deterioration of AP postural control present higher risk of serious injury. Most Studies usually used traditional balance measures, which provide descriptive information on the postural sway, however it is very difficult to understand the mechanism of postural

Table 5 Voluntary Step Execution Test times and the preparation phase times during single task and dual task conditions (mean \pm SD). Values are means \pm SD (95\% confidence interval for means). A full Bonferroni correction (a-level 0.05/2=0.025) was used for each of the two different task conditions (single and dual task condition) to achieve an overall significance level of 0.05

\begin{tabular}{|c|c|c|c|c|c|}
\hline & Group & Baseline & post-test & $\begin{array}{l}\text { ANOVA (Baseline } \\
\text { to post-test) T }\end{array}$ & $\begin{array}{l}\text { ANOVA (Baseline to } \\
\text { post-test) } T \times G\end{array}$ \\
\hline \multicolumn{6}{|l|}{ Single task condition } \\
\hline \multirow[t]{2}{*}{ Reaction Time (ms) } & Intervention & $215 \pm 40$ & $194 \pm 36$ & $F=0.002$ & $F=2.187$ \\
\hline & control & $219 \pm 70$ & $206 \pm 57$ & $p=0.968$ & $p=0.057$ \\
\hline \multirow[t]{2}{*}{ Foot Contact Time (ms) } & Intervention & $1065 \pm 16$ & $993 \pm 138$ & $F=0.474$ & $F=11.325$ \\
\hline & control & $1027 \pm 147$ & $1010 \pm 143$ & $p=0.495$ & $p=0.002$ \\
\hline \multicolumn{6}{|l|}{ Dual Task condition } \\
\hline \multirow[t]{2}{*}{ Reaction Time (ms) } & Intervention & $412 \pm 174$ & $346 \pm 99$ & $F=1.881$ & $F=7.322$ \\
\hline & control & $354 \pm 98$ & $339 \pm 100$ & $p=0.179$ & $p=0.010$ \\
\hline \multirow[t]{2}{*}{ Foot Contact Time (ms) } & Intervention & $1355 \pm 243$ & $1224 \pm 172$ & $F=0.439$ & $F=9.857$ \\
\hline & control & $1250 \pm 165$ & $1240 \pm 171$ & $p=0.512$ & $p=0.003$ \\
\hline
\end{tabular}

Note: Comparison of baseline and post-intervention between the two groups based on repeated measures ANOVA (Test $\times$ Group). Abbreviations: $G$ group, $T$ time, ms milliseconds 
control using traditional COP statistics, this we performed SDA. We found training effects on open- and close-loop control mechanism when vision was occluded as indicted by a significant decrease in Critical Displacement in AP direction $(C d y)$. . Improvements in and Short-term Effective diffusion coefficients in ML direction $(D x s)$ as well as a trend towards a decreased in Short-term Effective diffusion coefficients in AP direction (Dys) further support this notion. These parameters reflect the degree of sway in the short term region. A decreased tendency to continue sway in an ongoing direction (Table 4) indicates a behavior that reflects a more stable balance control system. This indicates that the intervention group was able to better detect COP movement under their feet and initiate a more effectively close loop balance control. These suggest that the improved closed-loop balance control when vision was occluded would likely be from proprioceptive and/or maybe vestibular sources.

The improvement in step execution in the intervention group was seen during the step execution times i.e., foot contact times, in both ST and DT (72 ms in ST and $131 \mathrm{~ms}$ in DT, see Table 5). A shorter step execution indicates improvement in the ability to prevent a fall if balance is lost, consequently, the risk of fall and injury maybe reduced [22-24]. The improvement in the step execution in the intervention group was accompanied with improvement in step reaction times, in particular under dual task conditions. The step reaction time duration is mainly dependent on sensory detection thresholds, nerve conduction velocities and central neural processing times. A shortened step reaction time in dual task condition suggests that the central neural processing time was improved as a result of perturbation training. This indicate that the executive functioning was improved, subject were able to step quickly while their attention was allocated elsewhere. The executive functioning is related to the ability to rapidly shift attention from a cognitive task to the stepping task. This could be interpreted also in terms of automaticity of the stepping behavior as an essential characteristic of the central reorganization process. Therefore, we could assume that the interference effect during dual task stepping was reduced as a result of the treadmill perturbation training.

Halvarsson et al. [15] also found significant improvements in stepping performance, in a group of elderly fallers that performed perturbation exercises. Melzer and Oddsson [14], Mansfield et al. [13] and Rogers et al. [44] also found that specific step training that includes perturbation of balance improves stepping abilities in older adults. Pai et al. [12] have shown reductions in falls and balance loss following a repeated-slip during walking exposure. The same group had further showed that those gains could be retained for 6 months [18] and cut older adults' annual risk of falls by $50 \%$ especially among elderlies who had history of falls [19]. Our results and the results above suggests that specificity-of-training principle is a major factor in achieving treatment goals and therapists need to tailor balance perturbation training programs to target functional aspects of balance control such as the ability to step rapidly [45].

It is still unknown how the improvement seen in balance and stepping carries over to real-life falls. It may be that carryover to fear of falls and physical performance as measure with POMA did exist but was not detected by these outcomes measures due to insufficient sample size or due to ceiling effects, subjects were close to score the highest score in both measures. We also did not find significant carryover effects on self-reported and performance based function. This suggests that function is not derived only by the ability to perform balance tasks, but is influenced by environmental and behavioral factors. Most perturbation training programs did not measure self-reported physical function [16-19, 40, 44]. However other studies found improvement in selfreported function [14] and fear of falls [15]. This two studies trained balance in a group setting adding also behavioral factors. This may suggest that physical intervention per-se without behavioral intervention cannot change the levels of physical function. The fact that Performance based measure are weakly associated with self-reported mobility in healthy elderly persons $(r=0.21-0.29)$ [46] support this notion.

This study has several limitations. First, the data came from a fairly small sample of independent older adults thus the results cannot be generalized to frail or institutionalized elderly persons. Second, the training program was done on a treadmill and not on leveled ground. Treadmill walking is somewhat different then over ground walking and might pose different demands on the trainee. However, it has been showed that fall-resisting skills acquired from such training can be transferred to over-ground walking [47]. Third, to provide stronger evidence of the clinical efficacy of this training procedure, future studies should compare the current intervention with an alternative treatment such as Tai Chi, or strength training as this was found beneficial in a recent review [48]. Also there is a need to determine whether this type of training improves the ability to cope with falls that resulted from slips and trips only, or can be transferred to any kind of loss of balance. Fourth, further research is needed in order to determine whether randomly ordered perturbations exercises (Random practice) would render better results than repeating the same perturbation exercises (blocked practice) in terms of acquisition, adaptation and retention.

\section{Conclusion}

Participation in a balance training program that includes unexpected perturbation of balance during treadmill walking reduced the risk factors for falls as presented by 
biomechanical markers that have been shown in the past to identify fallers and predict falls. However levels of physical functioning were not improved, this suggests that preventing sedentary lifestyle for the elderly require additional behavioral intervention.

\section{Competing interests}

IM and AS have developed and built the BaMPer perturbation system that was used in this project. All other authors declare that they have no competing interests.

\section{Authors' contributions}

IK was involved in planning the experiments and conducting the intervention as well as data analysis and interpretation and drafting of the manuscript. YG was involved in conducting the Pre and Post intervention tests as well as data interpretation and drafting of the manuscript. AS was involved in experimental design, data interpretation and drafting of the manuscript. RD was involved in Subject recruitment, medical screening as well as drafting and revising of the manuscript. YS was involved in Subject recruitment, medical screening as well as drafting and revising of the manuscript. IM was involved in planning the experiments and conducting the Pre and Post intervention tests as well as data analysis and interpretation and drafting of the manuscript. All authors read and approved the final manuscript.

\section{Acknowledgements}

This study was supported by a grant from the Israeli Ministry of Health (2011-056), and partially supported by the Helmsley Charitable Trust through the Agricultural, Biological and Cognitive Robotics Initiative of Ben-Gurion University of the Negev. The authors thank the volunteers who participated in this study and the management of Beit Yona and Ganei Omer, Israel for allowing us to use its facilities.

\section{Funding source}

This study was supported by a grant from the Israeli Ministry of Health (2011-056).

\section{Author details}

${ }^{1}$ Schwartz Movement Analysis \& Rehabilitation Laboratory, Department of Physical Therapy, Recanati School for Community Health Professions, Faculty of Health Sciences, Ben-Gurion University of the Negev, P.O.B. 653, Beer-Sheva 84105, Israel. ²Department of Mechanical Engineering, Faculty of Engineering, Ben-Gurion University of the Negev, Beer-Sheva, Israel. ${ }^{3}$ Orthopedic department, Barzilai Medical Center, Ashkelon, Israel. ${ }^{4 " B e i t}$ Yona" senior citizens home, Beer-Sheva, Israel.

\section{Received: 7 June 2015 Accepted: 12 February 2016}

Published online: 04 March 2016

\section{References}

1. Centers for Disease Control and Prevention, National Center for Injury Prevention and Control. Web-based Injury Statistics Query and Reporting System (WISQARS) [online]. Accessed August 15, 2013.

2. Stevens JA. Falls among older adults_risk factors and prevention strategies. J Saf Res. 2005;36(4):409-11.

3. Robinovitch SN, Feldman F, Yang Y, et al. Video capture of the circumstances of falls in elderly people residing in long-term care: an observational study. Lancet. 2013:381(9860):47-54.

4. Luukinen $\mathrm{H}$, Herala $\mathrm{M}$, Koski $\mathrm{K}$, et al. Fracture risk associated with a fall according to type of fall among the elderly. Osteoporosis Int. 2000;11(7):631-4.

5. Woollacott MH, Tang PF. Balance control during walking in the older adult: research and its implications. Phys Ther. 1997;77(6):646-60.

6. Maki BE, Mcllroy WE. The role of limb movements in maintaining upright stance: the "change-in-support" strategy. Phys Ther. 1997;77(5):488-507.

7. Maki BE, Mcllroy WE. Control of rapid limb movements for balance recovery: age-related changes and implications for fall prevention. Age Ageing. 2006; 35 Suppl 2:ii12-18.

8. Bierbaum S, Peper A, Karamanidis K, Arampatzis A. Adaptive feedback potential in dynamic stability during disturbed walking in the elderly. J Biomech. 2011;44(10):1921-6.
9. Bierbaum S, Peper A, Arampatzis A. Exercise of mechanisms of dynamic stability improves the stability state after an unexpected gait perturbation in elderly. Age (Dordr). 2013;35(5):1905-15. 10.

10. Arampatzis A, Peper A, Bierbaum S. Exercise of mechanisms for dynamic stability control increases stability performance in the elderly. J Biomech. 2011:44(1):52-8.

11. Shimada H, Obuchi S, Kamide N, et al. Relationship with dynamic balance function during standing and walking. Am J Phys Med Rehabil. 2003;82(7): 511-6.

12. Pai $Y$, Bhatt $T$, Wang $E$, et al. Inoculation against falls: rapid adaptation by young and older adults to slips during daily activities. Arch Phys Med Rehabil. 2010;91(3):452-9.

13. Mansfield A, Peters AL, Liu BA, et al. Effect of a perturbation-based balance training program on compensatory stepping and grasping reactions in older adults: a randomized controlled trial. Phys Ther. 2010;90(4):476-91.

14. Melzer I, Oddsson LI. Improving balance control and self-reported lower extremity function in community-dwelling older adults: a randomized control trial. Clin Rehabil. 2013;27(3):195-206.

15. Halvarsson A, Oddsson L, Olsson $E$, et al. Effects of new, individually adjusted, progressive balance group training for elderly people with fear of falling and tend to fall: a randomized controlled trial. Clin Rehabil. 2011; 25(11):1021-31

16. Grabiner MD, Bareither ML, Gatts S, et al. Task-specific training reduces trip-related fall risk in women. Med Sci Sports Exerc. 2012:44(12):2410-4.

17. Rosenblatt NJ, Marone J, Grabiner MD. Preventing trip-related falls by community-dwelling adults: a prospective study. J Am Geriatr Soc. 2013;61(9); 1629-31.

18. Bhatt T, Yang F, Pai Y. Learning to resist gait-slip falls: long-term retention in community-dwelling older adults. Arch Phys Med Rehabil. 2012;93(4):557-64.

19. Pai $Y C$, Bhatt $T$, Yang $F$, et al. Perturbation training can reduce communitydwelling older adults' annual fall risk: a randomized controlled trial. J Gerontol A Biol Sci Med Sci. 2014;69(12):1586-94.

20. Shapiro A, Melzer I. Short report balance perturbation system to improve balance compensatory responses during walking in old persons. J Neuroeng Rehabil. 2010;7:32.

21. Mansfield A, Wong JS, Bryce J, Knorr S, Patterson KK. Does perturbation-based balance training prevent falls? Systematic review and meta-analysis of preliminary randomized controlled trials. Phys Ther. 2015:95(5):700-9.

22. Melzer I, Kurz I, Shahar D, et al. Predicting injury from falls in older adults: comparison of voluntary step reaction times in injured and noninjured fallers-a prospective study. J Am Geriatr Soc. 2009;57(4):743-5.

23. Melzer I, Kurz I, Shahar D, et al. Do voluntary step reactions in dual task conditions have an added value over single task for fall prediction? A prospective study. Aging Clin Exp Res. 2010;22(5-6):360-6.

24. Melzer I, Kurz I, Shahar D, et al. Application of the voluntary step execution test to identify elderly fallers. Age Ageing. 2007;36(5):532-7

25. Melzer I, Benjuya N, Kaplanski J. Postural stability in the elderly: a comparison between fallers and non-fallers. Age Ageing. 2004;33(6):602-7.

26. Melzer I, Kurz I, Oddsson LI. A retrospective analysis of balance control parameters in elderly fallers and non-fallers. Clin Biomech (Bristol, Avon). 2010;25(10):984-8.

27. Kurz I, Oddsson L, Melzer I. Characteristics of balance control in older persons who fall with injury-a prospective study. J Electromyogr Kinesiol. 2013;23(4):814-9.

28. Layne CS, Abraham LD. Interactions between automatic postural adjustments and anticipatory postural patterns accompanying voluntary movement. Int J Neurosci. 1991;61(3-4):241-54

29. Collins JJ, De Luca CJ. Open-loop and closed-loop control of posture: a random-walk analysis of center-of-pressure trajectories. Exp Brain Res. 1993;95(2):308-18.

30. Collins J, De Luca C, Burrows A, et al. Age-related changes in open-loop and closed-loop postural control mechanisms. Exp Brain Res. 1995;104(3):480-92.

31. Melzer I, Shtilman I, Rosenblatt N, et al. Reliability of voluntary step execution behavior under single and dual task conditions. J Neuroeng Rehabil. 2007:4:16.

32. Melzer I, Oddsson LI. The effect of a cognitive task on voluntary step execution in healthy elderly and young individuals. J Am Geriatr Soc. 2004; 52(8):1255-62

33. Melzer I, Benjuya N, Kaplanski J. Age-related changes of postural control: effect of cognitive tasks. Gerontology. 2001;47(4):189-94.

34. Cohn NB, Dustman RE, Bradford DC. Age-related decrements in stroop color test performance. J Clin Psychol. 1984;40(5):1244-50. 
35. Haley SM, Jette AM, Coster WJ, et al. Late life function and disability instrument: II. Development and evaluation of the function component. J Gerontol A BiolSciMedSci. 2002;57(4):217-39.

36. Tinetti ME, Richman D, Powell $L$. Falls efficacy as a measure of fear of falling. J Gerontol. 1990;45(6):239-43.

37. Raîche $M$, Hébert $R$, Prince $F$, et al. Screening older adults at risk of falling with the tinetti balance scale. Lancet. 2000;356(9234):1001-2.

38. McMurdo ME, Millar AM, Daly F. A randomized controlled trial of fall prevention strategies in old peoples' homes. Gerontology. 2000;46(2):83-7.

39. Hedges L, Olkin I. Estimation of a single effect size: Parametric and nonparametric methods. Stat Methods Metaanal. 1985:75-106.

40. Pai YC, Bhatt TS. Repeated-slip training: an emerging paradigm for prevention of slip-related falls among older adults. Phys Ther. 2007;87(11):1478-91.

41. Laughton CA, Slavin M, Katdare K, et al. Aging, muscle activity, and balance control: physiologic changes associated with balance impairment. Gait Posture. 2003;18(2):101-8.

42. Lord SR, Rogers MW, Howland A, et al. Lateral stability, sensorimotor function and falls in older people. J Am Geriatr Soc. 1999;47(9):1077-81.

43. Maki BE, Holliday PJ, Topper AK. A prospective study of postural balance and risk of falling in an ambulatory and independent elderly population. J Gerontol. 1994;49(2):M72-84.

44. Rogers MW, Johnson ME, Martinez KM, et al. Step training improves the speed of voluntary step initiation in aging. J Gerontol A Biol Sci Med Sci. 2003:58(1):M46-51.

45. Horak FB, Henry SM, Shumway-Cook A. Postural perturbations: new insights for treatment of balance disorders. Phys Ther. 1997:77(5):517-33.

46. Simonsick EM, Newman AB, Nevitt MC, et al. Measuring higher level physical function in well-functioning older adults: expanding familiar approaches in the Health ABC study. J Gerontol A Biol Sci Med Sci. 2001; 56(10):M644-53.

47. Yang F, Bhatt T, Pai Y. Generalization of treadmill-slip training to prevent a fall following a sudden (novel) slip in over-ground walking. J Biomech. 2013; 46(1):63-9.

48. Gillespie LD, Robertson MC, Gillespie WJ, et al. Interventions for preventing falls in older people living in the community. Cochrane Database Syst Rev. 2012;9(11):CD007146

\section{Submit your next manuscript to BioMed Central and we will help you at every step:}

- We accept pre-submission inquiries

- Our selector tool helps you to find the most relevant journal

- We provide round the clock customer support

- Convenient online submission

- Thorough peer review

- Inclusion in PubMed and all major indexing services

- Maximum visibility for your research

Submit your manuscript at www.biomedcentral.com/submit 